\title{
Adaptação da técnica de repulsão de pré-molar para 0 tratamento da doença periodontal associada à fratura dentária e fístula mandibular em equino - relato de caso
}

Mariana Marcantonio Coneglian ${ }^{[a]}$, RAmiro das Neves Dias Neto ${ }^{[b]}$, Heloisa Godoi Bertagnon $n^{[c]}$, Sharlenne Leite da Silva Monteiro[c], Helcya Mime Ishiy Hulse ${ }^{[c]}$

\author{
[a] Pontifícia Universidade Católica do Paraná (PUCPR), Curitiba, PR, Brasil \\ [b] Universidade Estadual Paulista (UNESP), Botucatu, SP, Brasil \\ [c] Universidade Estadual do Centro-Oeste (UNICENTRO), Guarapuava, PR, Brasil
}

*Autor correspondente

e-mail: mmconeglian@yahoo.com.br

\section{Resumo}

A doença periapical (DP) é considerada uma das afecções mais graves dentro da odontologia equina, podendo evoluir para abscesso periodontal com ou sem fistulação e fratura dentária, levando a problemas de adaptação à embocadura, dificuldade na mastigação, emagrecimento progressivo e até cólicas por compactação. 0 diagnóstico da DP é realizado através da anamnese e exame da cavidade oral associados à avaliação radiológica. A escolha do tratamento baseia-se no grau de acometimento dentário e condição geral do paciente. Diferentes terapias são propostas: tratamento conservativo, extração intraoral e até procedimento cirúrgico, sendo a extração através da técnica de repulsão após trepanação a mais realizada; e para a realização da trepanação é indicada a realização de anestesia geral. 0 objetivo deste trabalho é relatar um caso de DP em equino envolvendo o elemento dentário 407, associada à fratura deste e tratamento através da extração dentária por repulsão, porém sem a necessidade de trepanação. Foi atendido no Hospital Veterinário da Universidade Estadual do Centro-Oeste um equino macho castrado, de aproximadamente 4,5 anos, apresentando há cinco meses um aumento de volume na borda ventral da mandíbula direita, de consistência dura, acompanhado de uma fístula de onde drenava secreção purulenta. Ao exame clínico, o equino apresentava parâmetros vitais dentro da normalidade, porém sua condição corporal estava abaixo do ideal e ainda apresentava uma leve redução da motilidade intestinal. 0 exame da cavidade oral revelou mobilidade anormal do elemento dentário 407, acompanhada de fratura deste e acúmulo de alimentos entre os dentes 406 e 407. 0 exame radiográfico confirmou a fratura, acompanhada de doença periodontal e reabsorção de parte da raiz do dente 407. Uma sonda metálica foi introduzida na fístula mandibular e nova radiografia foi realizada, indicando que o trajeto fistuloso desembocava exatamente no centro do 
elemento dentário 407. Inicialmente foi realizada uma tentativa de extração intraoral com animal em posição quadrupedal sob sedação, porém o procedimento não foi efetivo. Instituiu-se, portanto, tratamento conservativo através da lavagem da fistula mandibular e da cavidade oral com clorexidine $0,2 \%$ duas vezes ao dia, por cinco dias, e terapia antimicrobiana através da associação de Penicilina procaína e Gentamicina, obtendo-se, assim, condição favorável para a cirurgia através da técnica de repulsão de pré-molares. 0 equino foi submetido à anestesia geral e posicionado em decúbito lateral; um espéculo bucal foi utilizado, permitindo a introdução da mão da cirurgiã. Na técnica convencional realizaria-se a incisão da pele e periósteo sobre a área proposta de trepanação para, após esta, com auxílio de um rebatedor, realizar a repulsão do dente. No caso aqui descrito, entretanto, a trepanação não foi realizada e a própria fístula pré-existente foi utilizada, após curetagem, para a introdução do rebatedor e repulsão do dente, o que reduziu consideravelmente o tempo de cirurgia. Após a extração, realizou-se nova curetagem e um rolo de gaze foi introduzido para impedir acúmulo de alimentos no local. A gaze era trocada diariamente acompanhada de lavagens com clorexidine $0,2 \%$ intraoral e através da fístula, até o fechamento desta. A terapia antimicrobiana foi mantida por mais sete dias. Novas avaliações foram realizadas, observando cicatrização completa da fístula mandibular aos 15 dias e recuperação da condição corpórea aos 45 dias. Nova avaliação após seis meses foi recomendada para correção das possíveis alterações decorrentes da ausência deste elemento dentário; cuidado este que deverá continuar por toda a vida do animal. No presente relato, a cirurgia de extirpação de pré-molar mandibular através de fístula pré-existente mostrou-se eficiente, reduzindo o tempo de cirurgia e trazendo à tona uma possibilidade para a realização da técnica com o animal em posição quadrupedal, sob neuroleptoanalgesia, e para tal, novos estudos são necessários.

Palavras-chave: Odontologia equina. Doença periapical. Extirpação dentária. 